\title{
The baby with poor visual contact
}

Normally, full term babies show evidence of visual fixation at birth or shortly afterwards. ${ }^{1}$ Visual following responses have even been observed in prematurely born babies. ${ }^{2}$ The absence of visual responsiveness in a baby of more than 8 weeks old has to be taken seriously and warrants careful investigation. Parents are anxious to understand the reason why the baby seems not to see, and want to know the visual prognosis. Visual inattentiveness in a baby can be due to very heterogeneous causes. Obvious causes of visual impairment are bilateral cataracts, persistent hyperplastic primary vitreous, retrolental fibroplasia, chorioretinal colobomata, etc. However, in many babies no underlying cause can be found on routine ophthalmological examination. There are also many pitfalls. For example, the infantile optic disc can be paler than that of an older child and the macula and fundus may be more mottled, which could lead to erroneous diagnoses of optic atrophy and retinal pathology. An incorrect diagnosis of visual impairment in an infant can be devastating to the family. Clinical signs can be typical, but additional technical examinations are necessary in most patients.

\section{Visual development}

The normal function of the visual system in large part parallels the anatomical development. Prenatal development of the eye and brain occurs relatively early in comparison with other systems. By 6 weeks of gestation, the ocular structures and differentiation of the brain are fairly well developed. The visual system is relatively mature at birth. After birth differential growth of the eye occurs. The anterior structures are, in general, more completely developed than the posterior segment of the eye. In addition to the postnatal growth of the eye, the central visual system is also maturing. The timing of premature birth is significant for the immature visual system. ${ }^{3}$ Excluding those infants who have suffered complications of preterm birth, the development of visual acuity in the infant born before term appears to progress at a rate similar to his or her term counterpart-as though birth had occurred at term. ${ }^{45}$ Contrasting with these reports, superiority of acuity in preterm subjects has been documented in several behavioural and electrophysiological studies indicating the possible beneficial effects of the environment. ${ }^{67}$ Studies so far are relatively few, and more research is required to determine whether premature birth and its accompaniments either accelerate or retard any aspect of visual development. In prematurely born babies who suffered complications visual outcome is worse. Retinopathy of prematurity (ROP) is an important cause of ophthalmic morbidity in prematurely born babies. Clinical conditions of particular visual importance are those with neurological involvement. Besides ROP, hypoxia and periventricular leucomalacia, and intraventricular haemorrhage with visual pathway involvement can cause blindness in premature infants.

\section{Evaluation of visual function}

Establishing normal levels of visual function is, despite research efforts to quantify them, still primarily one of observation of behaviour. Behavioural observations have been described as prerequisites for a systematic neurological examination. ${ }^{8}$ By 2 months, a visual following response should be present, and the baby should smile responsively to a parent. At 4 months, a child should reach for an object. Visual evoked potentials and forced preferential looking (FPL) data show rapid improvement of grating resolution during the first months of life. With the first method, the infant's visual evoked potentials to stripe gratings or checkerboards of various sizes are recorded. Measurements with the FPL technique have suggested that an ability to resolve $20 / 100$ equivalent gratings is present by the age of 1 year and 20/20 equivalent gratings by the age of 3 years. ${ }^{9}$ With this technique interpretation of a child's ability to see is dependent upon a child's motor response. At toddler's age vision measurement becomes easier. At that age various tests have been described, such as the Ffooks test, the directional tests such as the E-test and Landolt C ring test, and picture tests such as the Kay picture test.

\section{Delayed visual maturation}

In the past, the term "delayed visual maturation" (DVM) has been used by several authors in different ways and several classifications of DVM have been proposed.

The first report of DVM was by Beauvieux in $1926 .{ }^{10} \mathrm{He}$ used the description "la pseudo-atrophie des nouveaunés" and "la dysgénésie myélinique" in babies with absent visual contact and with grey optic discs on funduscopy. Their vision subsequently improved, with normal coloration of the optic discs. In 1947 Beauvieux concluded that DVM is not a single clinical entity. He divided DVM in two broad categories. ${ }^{11}$ In the first category DVM is the sole abnormality, with rapid and complete recovery of vision by approximately 4 months of age. In the second category, because of associated problems such as strabismus, high refractive errors, or mental retardation, visual improvement was slower and less complete. In 1951 the condition was also labelled "papilla grisea" and "myelogenesis retarda" by Keiner. ${ }^{12}$ In 1960 Law reviewed the assessment of the apparently blind child. ${ }^{13}$ The term "delayed visual maturation" was coined by Illingworth in 1961 when he described two infants with isolated delayed visual maturation whom he believed to be otherwise neurologically normal. ${ }^{14}$ The patients described by Illingworth were relatively more retarded in visual recognition than in other functions of the body. More recently the condition was described as "dissociated visual development"15 and "visual developmental delay". ${ }^{16}$ A number of clinical reports on DVM have been published over the past few years. ${ }^{17-22}$ Particularly in the ophthalmic literature some authors had an optimistic tone regarding the final visual outcome in these patients. ${ }^{18} 1923$ Several authors have suggested that babies with delayed visual maturation are otherwise normal. ${ }^{15}{ }^{17}{ }^{24}$ However, some patients described later, were found to have neurological problems such as delayed motor development, speech delay, seizures, and mental retardation..$^{18} 192225$

Besides the Beauvieux classification, different other classifications for DVM were introduced. Uemura et al proposed a new classification consisting of type 1 in which DVM presents an isolated anomaly; whereas in type 2, DVM is associated with mental retardation or seizures; and in type 3 "ocular" anomalies are associated with DVM. ${ }^{16}$ These authors recognised that the simplistic notion that 
Table 1 Introduction of a new classification of poor visual contact

Group 1: Poor visual contact with or without nystagmus in a "normal" baby After clinical ophthalmological and electrophysiological investigation this group can be classified as follows:

congenital idiopathic nystagmus

underlying sensory defect

- isolated delayed visual maturation

Group 2: Poor visual contact in a neurologically abnormal baby

Group 3: Poor visual contact with obvious structural ocular abnormalities

infants with DVM simply have a temporary delay in achieving normal visual milestones is often incorrect. Indeed, it is not tenable to propose that infants with visual maturation delay are simply those whose visual attentiveness developed somewhat later than normal, just as some children walk relatively later than others in spite of the absence of any significant neurological problems. Uemura and others' classification was slightly modified by Fielder $e t$ al. Type 1 DVM was subdivided into $1 \mathrm{~A}$ and $1 \mathrm{~B}$, for infants without and with perinatal problems respectively, considering perinatal problems as a negative prognostic factor in the neurological outcome. ${ }^{25}$ In the most recent classification "infantile nystagmus" and all ocular conditions are included. ${ }^{26}$ The most common condition in type 3 DVM is "infantile nystagmus", and albinism was also included because the ocular symptoms at young age were considered comparable. Children with severe structural congenital ocular abnormalities often show limited visual improvement and therefore, as is proposed by Fielder et al, must fall into the spectrum of DVM. ${ }^{26}$ The classification is therefore expanded to type 4 DVM.

At the present time some authors remain convinced that the term delayed visual maturation should only be applied to those children who appear to be entirely normal except for their apparent poor visual function for their adjusted gestational age. ${ }^{22}$ Other authors claim that it is justified to include babies with neurological and structural ocular defects, as they can show visual improvement after some time. ${ }^{26}$

Because of the different understanding and classification of DVM, we propose to use DVM only in the narrow sense. For babies with poor visual contact with associated neurological problems or with structural ocular abnormalities we prefer to use "poor visual contact in association with ..." (Table 1).

When we are confronted with a baby who does not fix or follow we think it is useful to categorise at a first clinical ophthalmological examination (Table 1).

In an apparently normal baby with poor visual contact and no visible ocular structural abnormality, with or without nystagmus a careful and systematic examination is necessary. Beside the clinical ophthalmological examination the electrophysiological examination will help to differentiate an underlying sensory defect nystagmus from a congenital idiopathic nystagmus. An electrophysiological assessment is mandatory in every child with poor visual contact with or without nystagmus; there is no other means to rule out retinal pathology. A clear terminology of nystagmus is necessary: we propose to drop the term "congenital nystagmus" and "infantile nystagmus" and we define a nystagmus emerging before the age of 6 months as "early onset nystagmus". ${ }^{27}$ Only after a thorough clinical and electrophysiological examination can three groups be distinguished: congenital idiopathic nystagmus, sensory defect nystagmus, and neurological nystagmus. Albinism, which we consider as a structural ocular deficit, can be categorised in group 3. As mentioned before, we prefer to use DVM only for a normal baby with a transient visual deficit. Babies with associated neurological problems at presenta- tion are considered in group 2, and babies with visible structural ocular abnormalities in group 3. However, a normal perinatal history does not exclude the possibility of a neurological deficit on follow up. We therefore prefer not to subcategorise babies with DVM on this basis. Based on our observations in the clinic we noted that, with a longer follow up, more neurological problems emerged in all groups of babies with poor visual contact. We therefore propose a follow up till school age in a child presenting with "isolated delayed visual maturation" before considering the DVM as a "transient phenomenon in a normal baby".

In conclusion, the term delayed visual maturation has been used in different ways in the literature. The classifications have been extended more and more. It is important, when confronted with a baby with poor visual contact, that a clear terminology and classification are used. We wish to introduce a new classification of poor visual contact.

\section{CASTEELS W SPILEERS \\ L MISSOTTEN}

Department of Ophthalmology, St Rafael UZ, Leuven, Belgium

P CASAER

Department of Paediatrics, Gasthuisberg UZ, Leuven

Correspondence to: I Casteels, MD, Department of Ophthalmology, St Rafael UZ, Capucijnenvoer 33, B-3000 Leuven, Belgium.

1 Simons K, ed. Early visual development, normal and abnormal. New York: Oxford University Press, 1993.

2 Van Hof-van Duin J, Mohn G, Fetter WPF, et al. Preferential looking acuity in preterm infants. Behav Brain Res 1983;10:47-50.

3 Fielder AR, Foreman N, Moseley MJ, et al. Prematurity and visual development. In: Simons K, ed. Early visual development, normal and abnormal. New York: Oxford University Press, 1993:486-98

4 Fantz RL, Fagan JF, Miranda SB. Early visual selectivity as a function of pattern variables, previous exposure, age from birth and conception and expected cognitive defect. In: Cohen L, Salapatek P, eds. Infant perception from sensation to cognition. Orlando, FL: Academic Press, 1975:249-345.

5 Dobson V, Mayer DL, Lee CP. Visual acuity screening of preterm infants. Invest Ophthalmol Vis Sci 1980;19:1489-505.

6 Sokol S, Jones K. Implicit time of pattern evoked potentials in infants: an index of maturation of spatial vision. Vision Res 1979;19:747-55.

7 Norcia AM, Tyler CW, Piecuch R, et al. Visual acuity development in normal and abnormal preterm human infants. $\mathcal{F}$ Pediatr Ophthalmol Strabismus 1987;24:70-4.

8 Casaer P, Lagae L. Age specific approach to neurological assessment in the first year of life. Acta Paediatr Ұpn 1991;33:125-38.

9 Teller DY, McDonald MA, Preston K, et al. Assessment of visual acuity in infants and children: the acuity card procedure: a rapid test of infant acuity. Dev Med Child Neurol 1986;28:779-89.

10 Beauvieux M. La pseudo-atrophie optique des nouveau-nés (dysgénésie myélinique des vois optiques). Ann d'Oculistiques 1926;163:881-921.

11 Beauvieux M. La cécite apparente chez le nouveau-né: la pseudoatrophie grise du nerf optique. Arch d'Ophtalmol 1947;7:241-9.

12 Keiner GBJ. New viewpoints on the origin of squint. The Hague: Martinus Nijhof, 1951.

13 Law F. The problem of the visually defective infant. Trans Ophthalmol Soc UK 1960;80:3-12.

14 Illingworth RS. Delayed visual maturation. Arch Dis Child 1961;34:407-9.

15 Mellor DH, Fielder AR. Dissociated visual development: electrodiagnostic studies in infants who are 'slow to see'. Dev Med Child Neurol 1980;22:327-35.

16 Uemura Y, Oguschi Y, Katsumi O. Visual developmental delay. Ophthalmic Pediatr Genet 1981;1:49-58.

17 Harel S, Holtzman M, Feinsod M. Delayed visual maturation. Arch Dis Child 1983;58:298-9.

18 Hoyt CS, Jastrzebski G, Marg E. Delayed visual maturation in infancy. Br $\mathcal{F}$ Ophthalmol 1983;67:127-30.

19 Cole GF, Hungerford J, Jones RB. Delayed visual maturation. Arch Dis Child 1984;59:107-10

20 Editorial. Delayed visual maturation. Lancet 1984;1:1158-9.

21 Lagae L, Casaer P, Ceulemans B, et al. Bestaan er kinderen die laat zien? Tijdschr voor Geneeskunde 1988;44:147-52.

22 Lambert SR, Kriss A, Taylor D. Delayed visual maturation: a longitudinal study: clinical and electrophysiological assessment. Ophthalmology 1989;96: 524-8.

23 Harel S, Holtzman M, Feinsod M. The late visual bloomer. In: Harel S, Anastasion N, eds. The at risk infant: psychosocial/medical aspects. Baltimore: Anastasion N, eds. The at risk infant: psychosocial

24 Dudgeon J. Electrodiagnostic tests in visual assessment in children. Dispensing Optician 1977;29:222-9.

25 Fielder AR, Russell-Eggitt IR, Dodd KL, et al. Delayed visual maturation. Trans Ophthalmol Soc UK 1985;104:653-61.

26 Fielder AR, Mayer DL, Fulton AB. Delayed visual maturation. Lancet 1991; 337:1350.

27 Casteels I, Harris C, Shawkat F, et al. Nystagmus in infancy. Br F Ophthalmol 1992;76:434-7. 